\title{
Secondary Cerebellar Cortex Injury in Albino Male Rats after MCAO: A Histological and Biochemical Study
}

\author{
Aziza R. Alrafiah (iD \\ Medical Laboratory Technology Department, Faculty of Applied Medical Sciences, King Abdulaziz University, \\ Jeddah 21589, Saudi Arabia; aalrafiah@kau.edu.sa; Tel.: +966-01264-01000 (ext. 23495); \\ Fax: +966-01264-01000 (ext. 21686)
}

Citation: Alrafiah, A.R. Secondary Cerebellar Cortex Injury in Albino Male Rats after MCAO: A

Histological and Biochemical Study. Biomedicines 2021, 9, 1267. https:// doi.org/10.3390/biomedicines9091267

Academic Editor: Juan Gambini

Received: 28 August 2021

Accepted: 14 September 2021

Published: 18 September 2021

Publisher's Note: MDPI stays neutral with regard to jurisdictional claims in published maps and institutional affiliations.

Copyright: (C) 2021 by the author. Licensee MDPI, Basel, Switzerland. This article is an open access article distributed under the terms and conditions of the Creative Commons Attribution (CC BY) license (https:// creativecommons.org/licenses/by/ $4.0 /)$.
Abstract: The present study focused on secondary injury following the middle cerebral artery (MCA) occlusion in rats not linked to the MCA's feeding zone. This entity has been very rarely studied. Additionally, this study investigated the rates of expression of five fundamental angiogenic biomarkers called endoglin, vascular endothelial growth factors-A (VEGF-A), endothelin-1 (ET-1), 2granulocyte colony-stimulating factor (G-CSF), and angiopoietin-using the MCA occlusion (MCAO) model. The random allocation of twelve adult male albino rats was in two groups. As a sham control group, six rats were used. This group was subjected to a sham operation without MCAO. The MCAO group consisted of six rats that were subjected to MCAO operation. After three days, the rats were sacrificed. The cerebellar specimens were immediately processed for light microscopic examination. An angiogenic biomarkers multiplex assay from multiplex was used to assess endoglin levels, VEGFA, ET-1, angiopoietin-2, and G-CSF in serum samples. Hematoxylin and eosin-stained sections showed that the cerebellar cortex of rats of the MCAO group was more affected than the sham control group. Furthermore, Nissl stain and immunohistochemical analysis revealed an apparent increase in the number of positive immunoreactive in the cerebellar cortex and an evident decrease in Nissl granules in Purkinje cells of the MCAO rats, in contrast to the control rats. In addition, there was a significant increase in angiogenic factors VEGF-A, ET-1, angiopoietin-2, and endoglin. Interestingly, there was an increase in the G-CSF but a non-significant in the MCAO rats compared to the control rats. Furthermore, there was a significant correlation between the angiopoietin-2 and ET-1, and between G-CSF and ET-1. VEGF-A also exhibited significant positive correlations with the G-CSF serum level parameter, Endoglin, and ET-1. Rats subjected to MCAO are a suitable model to study secondary injury away from MCA's feeding zone. Additionally, valuable insights into the association and interaction between altered angiogenic factors and acute ischemic stroke induced by MCAO in rats.

Keywords: middle cerebral artery occlusion; cerebellar cortex; angiogenic factors; secondary injury

\section{Introduction}

Ischemic stroke is a severely impaired and high-incidence neurodegenerative condition. About $80 \%$ of all human strokes are ischemic strokes. They are caused by thrombotic and embolic occlusion that reduces or restricts blood flow in the MCA. The MCA is one of the main blood supplies in the brain [1].

Every year, about 15 million people suffer from strokes worldwide, according to the World Health Organization (WHO). Five million become permanently disabled, and five million die [2]. Stroke is becoming more and more of a critical health issue in the Middle East region, with the prediction that deaths caused by stroke will almost double by 2030 [3]. Stroke is recorded in Saudi Arabia as a rapidly increasing issue and a significant cause of disease and death. It is, therefore, one of Saudi Arabia's most crucial social and economic problems [4].

Von Monakow invented the term "diaschisis", defining it as the transient functional shock of regions distant from the lesion [5]. Various diaschisis patterns have been estab- 
lished. In 1981, in the presence of a hemispheric stroke, Baron et al. described crossed cerebral diaschisis (CCD) [6], a supratentorial lesion that causes hypoperfusion and hypometabolism in the contralesionally cerebellar hemisphere. However, the etiology of CCD is unknown [7]. To date, CCD mechanisms have been thought to start by interrupting the exiting input of the cerebellum, primarily through a cortico-pontocerebellar pathway $[8,9]$.

The most focal model of brain ischemia is the occlusion of a significant brain vessel, such as the mid-cerebral artery (MCA). The MCAO means that brain flow in the striatum and cerebral cortex exhibited various reduction degrees, depending on the method. The occlusion of the MCA in rats usually leads to extensive neuronal cortex loss and caudal putamen damage that ranges from very little to extensive $[1,10,11]$. This model has pathological findings that are similar to those reported by human stroke victims.

One of the critical early events after cerebral ischemia is angiogenesis [12]. The animal models provide an opportunity to develop preventive strategies to reduce ischemic brain injury and restore severe impairment. The use of pro-angiogenic stimulation, in particular, is the chance to promote neurogenesis and reconstruction of ischemic brain areas that lack adequate collateral vasculature infusion. A deeper understanding of how pro-angiogenic impulses in the brain affect neuronal activity is necessary [13]. The VEGFs are the essential mediators of vasculogenesis and angiogenesis and show upregulation after occlusion of the MCA in rats. In addition, angiopoietin- 2 has been identified as a vascular-specific receptor essential for vessel development [12]. Endothelial cells in cerebral blood vessels under the influence of astrocytes formed a blood-brain barrier (BBB). There is an increasing BBB permeability with humoral agents liberated by astrocytes, namely endothelin1 (ET-1) [14]. Lo and his colleagues suggested a role of ET-1 in BBB disruption in brain injury [15]. Granulocyte colony-stimulating factor (G-CSF) is a hematopoietic system endogenous peptide hormone currently undergoing phase I and II ischemic stroke clinical trials $[16,17]$. Several animal studies have shown that G-CSF has the potential to provide significant neuroprotection in brain ischemia, primarily because of high hormone-induced anti-apoptotic signals in the brain [18].

So, the current study aimed to focus on secondary injury following occlusion of the MCA in rats not linked to the feeding zone of the MCA. This entity has been very rarely studied. In addition, the purpose of this study was to investigate the rates of expression of five fundamental angiogenic biomarkers called angiopoietin-2, vascular endothelial growth factor-A (VEGF-A), endoglin, granulocyte colony-stimulating factor (G-CSF), and endothelin-1 (ET-1) using the MCA occlusion (MCAO) model.

\section{Materials and Methods}

\subsection{Biochemicals}

MULTIPLEX MAP Mouse Angiogenesis/Growth Factor Magnetic Bead Panel (Cat. \# MAGPMAG-24K) was used for the quantification of any or all of the following analytes in serum: Angiopoietin-2 Bead (Cat. \# MANGPT2-MAG), Endoglin Bead (Cat. \# MENDGLNMAG). Endothelin-1 Bead (Cat. \# MET1-MAG), G-CSF Bead (Cat. \# MGCSF-MAG), and VEGF-A Bead (Cat. \# MVEGFC-MAG). All the kits were purchased from (Merck Millipore, Burlington, MA, USA).

\subsection{Animals}

Twelve adult male albino rats weighing $280-340 \mathrm{~g}$ at the beginning of the experiment. The animals were delivered to an animal house at King Fahd Medical Research Center, pharmacology department, Faculty of Medicine, King Abdulaziz University (KAU), Jeddah, Saudi Arabia. Animals were kept at a temperature of $23.2{ }^{\circ} \mathrm{C}, 12: 12$-h light/dark cycle, and were given free access to water and food in a group of six animals per cage. A sevenday adaptation period to the new environment was allowed before assigning subjects to the study groups. Restrictions to food (but not water) were applied $24 \mathrm{~h}$ before the MCA occlusion operation. All experiments were conducted during the light phase from 10:00 a.m. To 4:00 p.m. 


\subsection{Induction of Middle Cerebral Artery Occlusion (MCAO)}

The intra-aluminum filament techniques, as described previously by Longa et al. [19], were used to develop an MCAO mode and modified to use an internal carotid artery (ICA) [20]. This simple technique is wholly noninvasive and was familiar to research neuroprotection mechanisms as well as cellular injury. The MCAO model includes the injection into the internal carotid artery (ICA) of a monofilament nylon suture 4-0, and then the cranial advancing of the suture. After $60 \mathrm{~min}$ (transient occlusion), the suture was removed.

\subsection{Experimental Groups}

The random allocation of twelve adult male albino rats was in two groups. As for the sham control group, six rats were used. This group underwent a sham operation. The $\mathrm{MCAO}$ group consisted of six rats subjected to MCAO operation. After three days, the rats were sacrificed by cervical dislocation under humane conditions, and the heads were dissected for obtaining the cerebellar biopsies. The specimens were immediately processed for light microscopic examination.

\subsection{Blood Sample Collection and Preparation}

From the ophthalmic venous plexus, the blood sample was collected through the retro-orbital approach. The blood was allowed to coagulate for at least $30 \mathrm{~min}$ before centrifugation to acquire serum aliquoted and stored at $-20{ }^{\circ} \mathrm{C}$ and then used to calculate concentrations of angiogenic biomarkers. The procedure of measuring angiogenic biomarkers based on antigen-antibody reaction on immunoassay machines, called Luminex 200, is available in the central laboratory of the medical college at KAU.

\subsection{Biochemical Measurements}

MULTIPLEX ${ }^{\circledR}$ MAP builds on Lumine ${ }^{\circledR} \mathrm{xMAP}^{\circledR}$ technology—one of the most rapidly expanding and valued multiplex technologies that serves life science applications and bioassays. Luminex ${ }^{\circledR}$ uses advanced methods to internally color-code microspheres of two fluorescent dyes internally color code. The exact quantities of these dyes may be used to create separately colored bead sets of $5005.6 \mu \mathrm{m}$ or $806.45 \mu \mathrm{m}$ polystyrene microsphere, each protected by a different primary antibody. After an observer extracts the bead from the test sample, a biotinylated detection antibody is added. Streptavidin then incubates the reaction mixture to complete a reaction on the surface of each microsphere. In the presence of the 3.1 Xponent software package, the levels of Angiopoietin-2, Endoglin, Endothelin-1, G-CSF, VEGF-A in processed serum were calculated using Luminex technology.

\subsection{Histological and Immune-Histochemical Studies for Light Microscopic Examination}

In a $10 \%$ buffer paraformaldehyde, the cerebellum specimens were fixed for $48 \mathrm{~h}$. The samples were dehydrated for 1 hour each in upward grades of alcohol $(50 \%, 70 \%, 90 \%$, and $95 \%)$. Next, two changes for one hour of absolute alcohol (100\%) were done. After xylene clearing, we incorporated soft paraffin wax at $55^{\circ} \mathrm{C}$ for $2 \mathrm{~h}$, and then repeated the process for another $2 \mathrm{~h}$ using hard paraffin at $60^{\circ} \mathrm{C}$. Five $\mu \mathrm{m}$ thick sections were prepared for hematoxylin and eosin (H\&E) staining. The stain of Nissl is used to stain Nissl substance in the cytoplasm of neurons. Additionally, the avidin-biotin-peroxidase technique was used to evaluate astrocytes glial fibrillary acidic protein (GFAP) counterstained with Hx. The positive reaction appeared as a brownish cytoplasmic reaction.

\subsection{Statistical Analysis}

Statistical analysis was conducted using the Statistical Package for the Social Science software package (SPSS) version 26.0 (IBM Corp., Armonk, NY, USA). All data were statistically analyzed using an unpaired student $t$-test. Correlations between measured parameters were made using Pearson correlations. Data are presented as mean \pm standard 
deviation (S.D.). The significance was at $\leq 0.05$. Graphs were made by GraphPad prism software version 8 (2019), San Diego, CA, USA.

\section{Results}

\subsection{Histological Results}

3.1.1. Hematoxylin and Eosin (H\&E)

Sham Control Group

Cerebellar cortex sections from H\&E of the sham control group rats revealed that it formed in three consecutive layers. The molecular layer was on the outside, followed by the layer of Purkinje cells, whereas the granular layer was on the inside (Figure 1A). Purkinje cells appeared flask-shaped with apical dendrites. In one row, they were set. Characteristics of this were a pale basophilic cytoplasm and a central vesicular nucleus. Tightly packed granule cells and cerebellar islands appeared in the granular cell layer (Figure 1B,C).

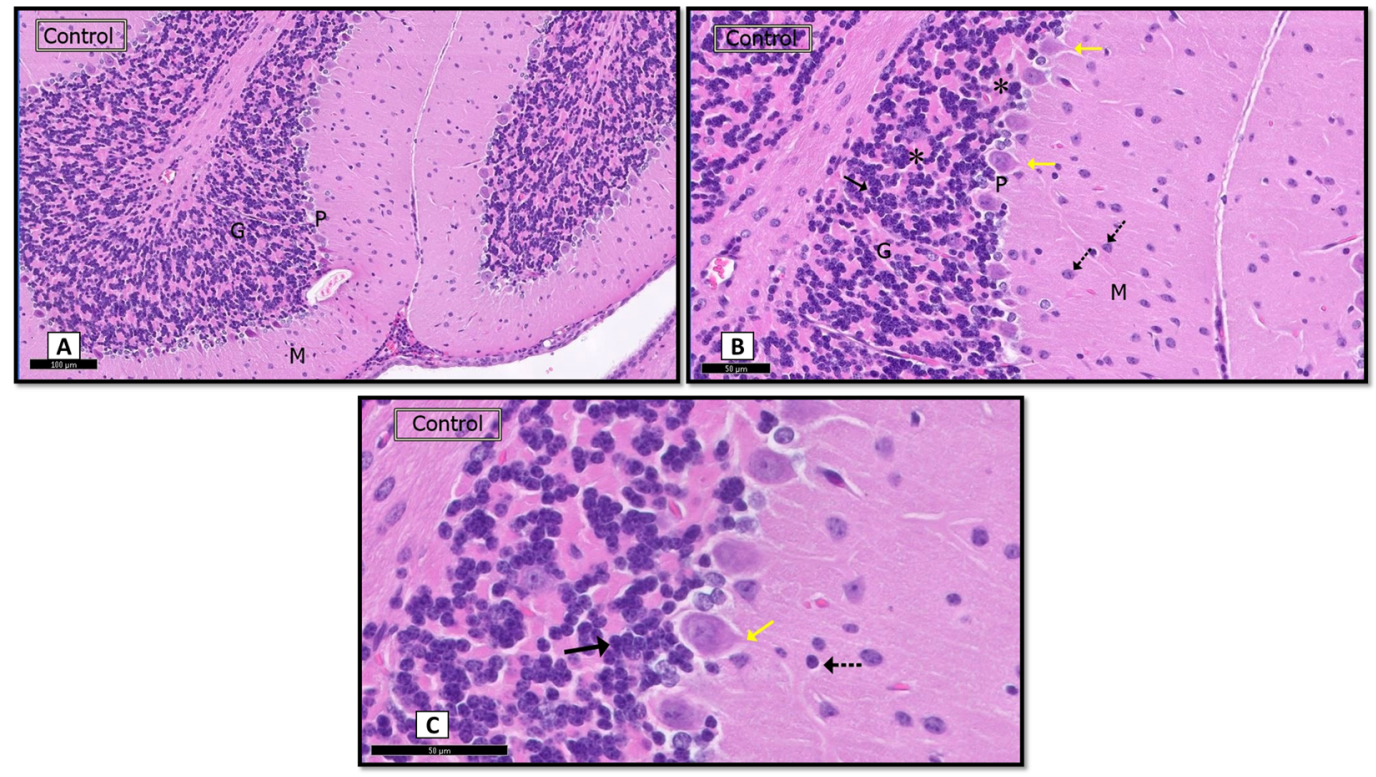

Figure 1. A section of a control rat showing: (A) the three layers; molecular (M), Purkinje cell (P), and granular cell layers (G). $($ H\&E. $\times 10$; Scale bar $=100 \mu \mathrm{m}) .($ B,C) The Purkinje cells $(P)$ in one row. Notice flask-shaped Purkinje cells with apical dendrites (yellow $\uparrow)$, pale stained nuclei, and prominent nucleoli. The granular layer appears consisting of closely packed rounded granule cells with rounded pale vesicular nuclei (Black arrow). Notice molecular layer (M) shows many glial cells ( $\operatorname{dot} \uparrow)$ and the spaces of cerebellar islands $\left({ }^{*}\right)$. (H\&E. $\mathbf{B} \times 20, \mathbf{C} \times 40$; Scale bar $\left.=50 \mu \mathrm{m}\right)$.

\section{MCAO Group}

Stained sections with H\&E showed that the cerebellar cells of rats of the MCAO group were more affected than the sham control group. Degenerated Purkinje cells were seen with darkly stained cytoplasm and nuclei. Additionally, halos were observed in empty spaces surrounding degenerated Purkinje cells. On the other hand, the granular layer cells were almost healthy, with some spaces between them (Figure 2A,B).

\subsubsection{Nissl Stain}

Purkinje cells' cytoplasm appeared with an apparent increase in the Nissl's granules surrounding central vesicular nuclei (Figure 3A). Interestingly, some Purkinje cells were lightly stained compared to the sham control group with an apparent reduction in their Nissl's granules content (Figure 3B). 


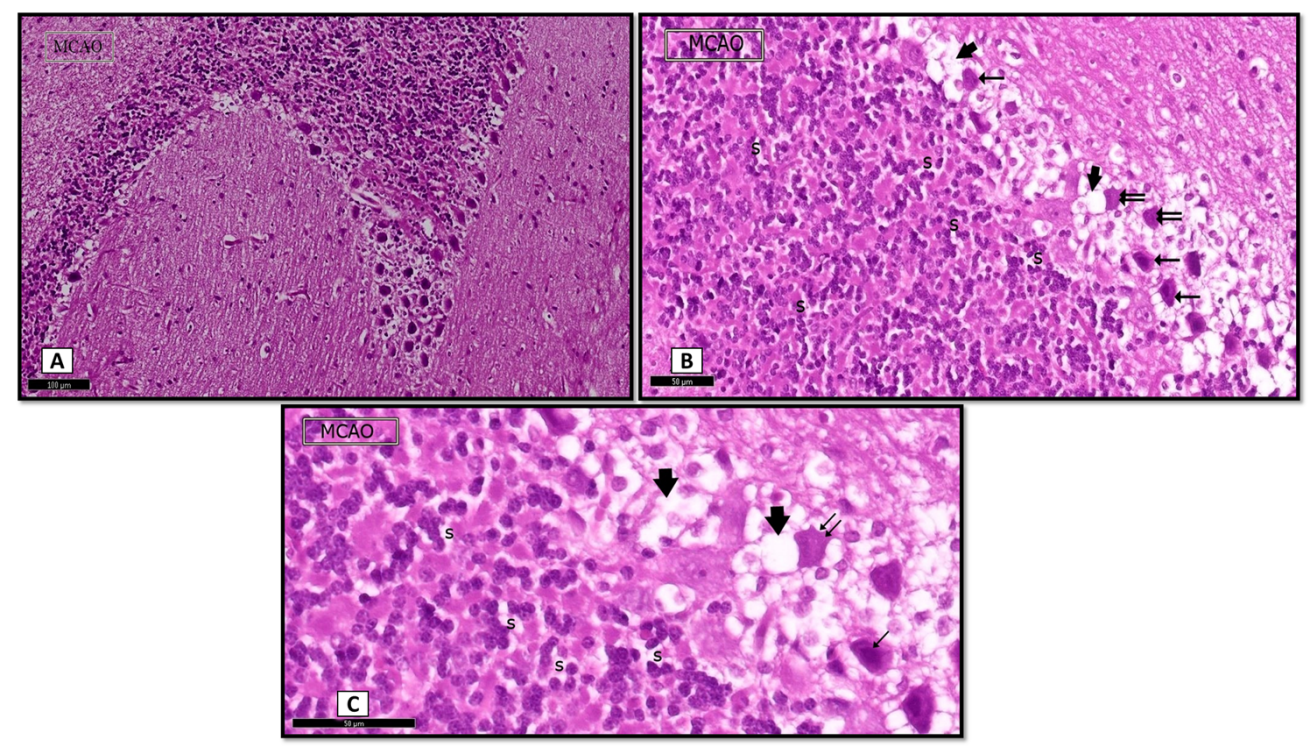

Figure 2. A section of MCAO rat showing: (A) the cerebellar cells of rats of the MCAO group shows destructive changes variable in severity and distribution. (B) Some Purkinje cells with homogenized cytoplasm and faint nuclei $(\uparrow \uparrow)$. Notice vacuolation within the nearby molecular layer (Thick arrow). Granular layers show some spaces (s). (C) Higher magnification (H\&E. A $\times 20$, B $\times 40$; Scale bar $=50 \mu \mathrm{m})$.
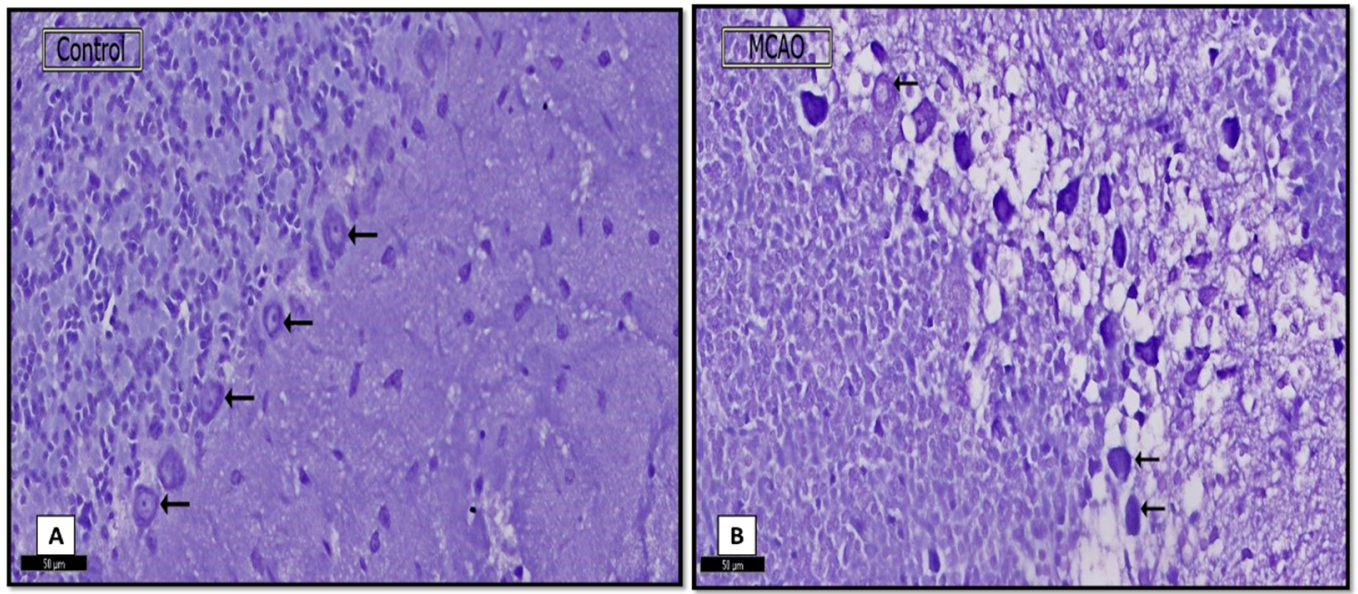

Figure 3. A Nissl-stained sections showing: (A) (control group) most of the Purkinje cells with Nissl's granules $(\uparrow)$ in their cytoplasm. (B) (MCAO group) Some Purkinje cells with marked reduction of Nissl's granules $(\uparrow)$ giving the faint cytoplasm appearance. (Nissl stain. $\times 20$; Scale bar $=50 \mu \mathrm{m}$ ).

\subsubsection{Immunostained GFAP Sections}

Immunostained sections of the sham control rats showed few GFAP positive immunopositive astrocytes dispersed in the layers of the cerebellar cortex (Figure 4A). Interestingly, an apparent increase in the number of immunopositive cells in all layers contrasts with the shame control group (Figure 4B).

\subsection{Biochemical Results}

In the current study, five fundamental angiogenic biomarkers named VEGF-A, angiopoietin2, endoglin, endothelin-1, and G-CSF were investigated in the MCAO group versus the control group (Figure 5 and Table 1). 


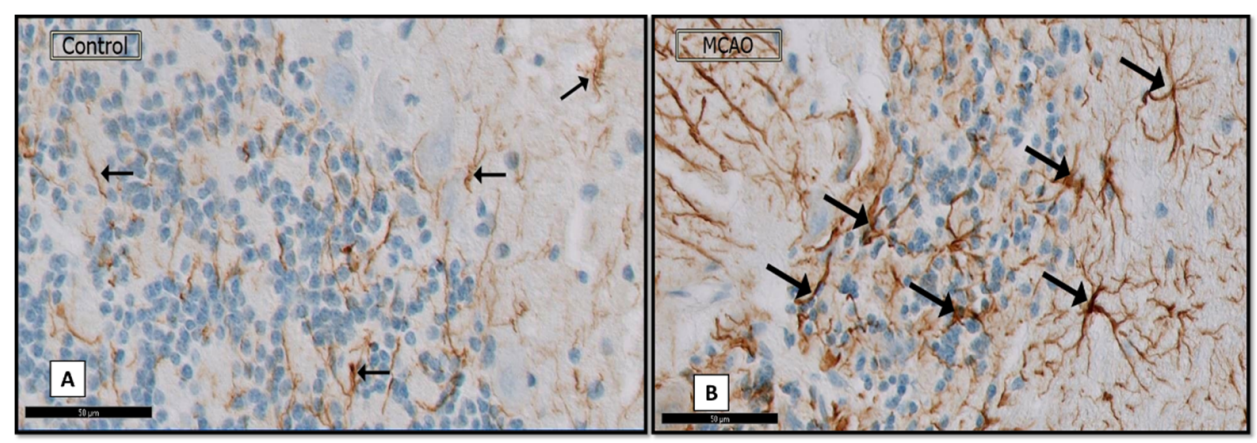

Figure 4. A section showing: (A) (control group) mild GFAP positive immunoreactive astrocytes ( $\uparrow$ ). (B) (MCAO group) strong GFAP positive immunoreactive astrocytes $(\uparrow)$. (GFAP $\times 40$; Scale bar $=50 \mu \mathrm{m})$.

A

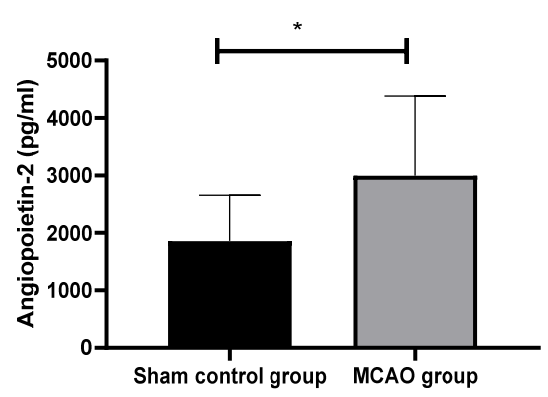

C

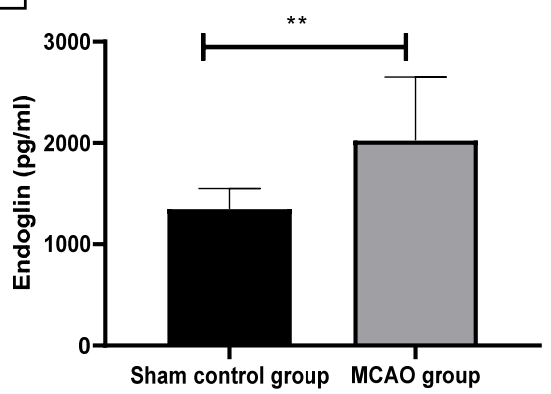

国

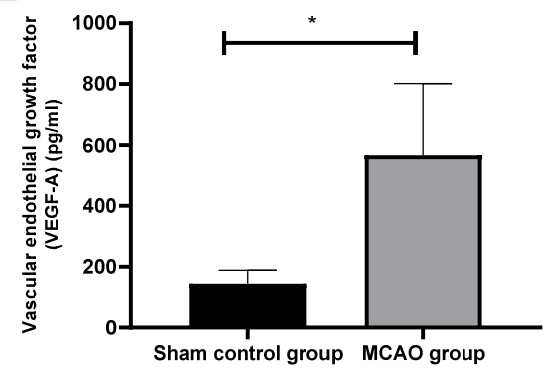

回

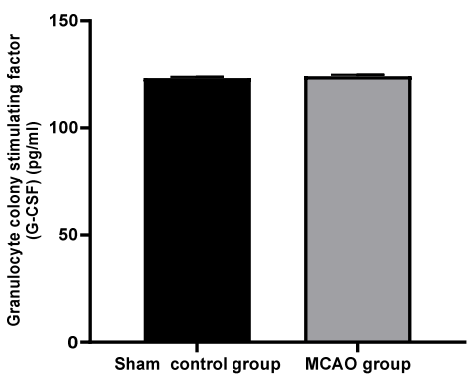

D

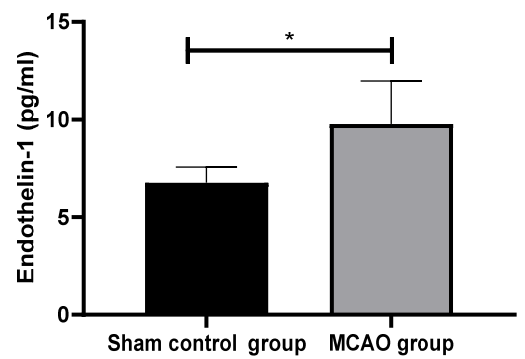

Figure 5. Comparison of angiogenic markers levels (A) Angiopoietin-2 (pg/mL), (B) Granulocyte colony-stimulating factor (G-CSF) (pg/mL), (C) Endoglin (pg/ml), (D) Endothelin-1 (ET-1) (pg/mL), (E) Vascular endothelial growth factor-A (VEGF-A) $(\mathrm{pg} / \mathrm{mL})$ between sham control group and middle cerebral artery occlusion (MCAO) group. Data are expressed as mean $+/-$ standard deviation. * Significant at $(<0.05)$ and ${ }^{* *}$ significant at $(<0.01)$ as compared to the sham control group. 
Table 1. Comparison of angiogenic factors between control rats and middle cerebral artery occlusion rats.

\begin{tabular}{|c|c|c|c|c|}
\hline & Group & $\mathbf{N}$ & $\begin{array}{l}\text { Mean } \pm \text { Std. } \\
\text { Deviation }\end{array}$ & Significance \\
\hline \multirow{2}{*}{ Angiopoietin-2 (pg/mL) } & sham control group & 6 & $1859.66 \pm 798.30$ & \multirow{2}{*}{$0.013 *$} \\
\hline & MACO group & 6 & $2997.50 \pm 1383.26$ & \\
\hline \multirow{2}{*}{$\begin{array}{l}\text { Granulocyte colony stimulating } \\
\text { factor }(\mathrm{G}-\mathrm{CSF})(\mathrm{pg} / \mathrm{mL})\end{array}$} & sham control group & 6 & $123.39 \pm 0.51$ & \multirow{2}{*}{0.197} \\
\hline & MACO group & 6 & $124.15 \pm 0.71$ & \\
\hline \multirow{2}{*}{ Endoglin $(\mathrm{pg} / \mathrm{mL})$} & sham control group & 6 & $1349.50 \pm 202.77$ & \multirow{2}{*}{$0.008^{* *}$} \\
\hline & MACO group & 6 & $2025.70 \pm 626.25$ & \\
\hline \multirow{2}{*}{ Endothelin-1 (ET-1) (pg/mL) } & sham control group & 6 & $6.76 \pm 0.80$ & \multirow{2}{*}{$0.01 *$} \\
\hline & MACO group & 6 & $9.78 \pm 2.19$ & \\
\hline \multirow{2}{*}{ VEGF-A (pg/mL) } & sham control group & 6 & $144.12 \pm 44.50$ & \multirow{2}{*}{$0.02 *$} \\
\hline & MACO group & 6 & $566.68 \pm 235.12$ & \\
\hline
\end{tabular}

Values are set as mean \pm S.D. Significance between sham control group and MCAO group using unpaired student $t$ test. * Significant at $(<0.05),{ }^{* *}$ significant at $(<0.01)$.

\subsubsection{Angiopoietin-2 (pg/mL)}

In the current study, Angiopoietin-2 levels in the MCAO rats significantly increased ( $p$-value $<0.05)$ versus the sham control rats, as shown in Figure 5A. Angiopoietin-2 level revealed concentrations of $(2997.50 \pm 1383.26 \mathrm{pg} / \mathrm{mL})$ in the serum of the MCAO group and $(1859.66 \pm 798.30 \mathrm{pg} / \mathrm{mL})$ for the sham control group.

\subsubsection{Granulocyte Colony-Stimulating Factor (G-CSF)}

In this study, the G-CSF level exhibited a non-significant increase $(p=1.97)$ in the MCAO group versus the sham control group, as shown in Figure 5B. The G-CSF level concentrations $(124.15 \pm 0.71 \mathrm{pg} / \mathrm{mL})$ for the MCAO group and the sham control group was $(123.39 \pm 0.51 \mathrm{pg} / \mathrm{mL})$.

\subsubsection{Endoglin}

In the current study, the serum level of Endoglin revealed a significant $(p=0.008)$ increase in the MCAO rats versus the control rats in Figure 5C. The Endoglin level concentrations $(1349.50 \pm 202.77 \mathrm{pg} / \mathrm{mL}$ ) for the MCAO group and for the sham control group was $(2025.70 \pm 626.25 \mathrm{pg} / \mathrm{mL})$.

\subsubsection{Endothelin-1 (ET-1)}

In the current study, ET-1 levels in the MCAO rats significantly $(p=0.01)$ increased versus the sham control rats, as shown in Figure 5D. The ET-1 level revealed concentrations of $(9.78 \pm 2.19 \mathrm{pg} / \mathrm{mL})$ in the serum of the MCAO group and $(6.76 \pm 0.80 \mathrm{pg} / \mathrm{mL})$ for the sham control group.

\subsubsection{Vascular Endothelial Growth Factor-A (VEGF-A)}

In the present study, the VEGF-A level exhibited a significant increase $(p=0.02)$ in the MCAO rats versus the sham control rats, as shown in Figure 5E. The VEGF-A level concentrations $(566.68 \pm 235.12 \mathrm{pg} / \mathrm{mL})$ for the MCAO group and for the sham control group was $(144.12 \pm 44.50 \mathrm{pg} / \mathrm{mL})$.

\subsubsection{Pearson's Correlation between Angiogenesis Markers among the Groups}

In the present study, the Pearson correlation test for all correlations among all study groups was used. Table 2 and Figure 6 showed a significant positive correlation between Angiopoietin-2 and ET-1 ( $r=734, p=0.007)$. Interestingly, the comparison groups showed significant positive correlations between G-CSF and ET-1 in the serum level parameter 
$(\mathrm{r}=0.599, p=0.04)$. In addition, VEGF-A also exhibited significant positive correlations with the G-CSF serum level parameter $(\mathrm{r}=0.755, p=0.005)$, Endoglin $(\mathrm{r}=0.827, p=0.001)$, and ET-1 $(\mathrm{r}=0.740, p=0.006)$.

Table 2. Pearson correlations between angiogenesis markers among the two groups of the study (sham control group and MCAO group).

\begin{tabular}{|c|c|c|c|c|c|}
\hline & & $\begin{array}{l}\text { Angiopoietin-2 } \\
\text { (pg/mL) }\end{array}$ & G-CSF (pg/mL) & $\begin{array}{l}\text { Endoglin } \\
(\mathrm{pg} / \mathrm{mL})\end{array}$ & $\begin{array}{r}\text { Endothelin-1 } \\
(\text { ET-1) }(\mathrm{pg} / \mathrm{mL})\end{array}$ \\
\hline \multirow{2}{*}{ G-CSF (pg/mL) } & Pearson Correlation & 0.303 & & & \\
\hline & Sig. (2-tailed) & 0.339 & & & \\
\hline \multirow{2}{*}{ Endoglin (pg/mL) } & Pearson Correlation & 0.344 & 0.474 & & \\
\hline & Sig. (2-tailed) & 0.274 & 0.120 & & \\
\hline \multirow{2}{*}{$\begin{array}{l}\text { Endothelin-1 (ET-1) } \\
\qquad(\mathrm{pg} / \mathrm{mL})\end{array}$} & Pearson Correlation & $0.734^{* *}$ & $0.599 *$ & 0.462 & \\
\hline & Sig. (2-tailed) & 0.007 & 0.040 & 0.131 & \\
\hline \multirow{2}{*}{ VEGF-A (pg/mL) } & Pearson Correlation & 0.472 & $0.755^{* *}$ & $0.827^{* *}$ & $0.740 * *$ \\
\hline & Sig. (2-tailed) & 0.121 & 0.005 & 0.001 & 0.006 \\
\hline
\end{tabular}

The correlation coefficient was made using the Pearson test. Middle cerebral artery occlusion (MCAO), Granulocyte colony-stimulating factor (G-CSF), Vascular endothelial growth factor-A (VEGF-A). ${ }^{* *}$ Correlation is significant at the 0.01 level (2-tailed). ${ }^{*}$ Correlation is significant at the 0.05 level (2-tailed).
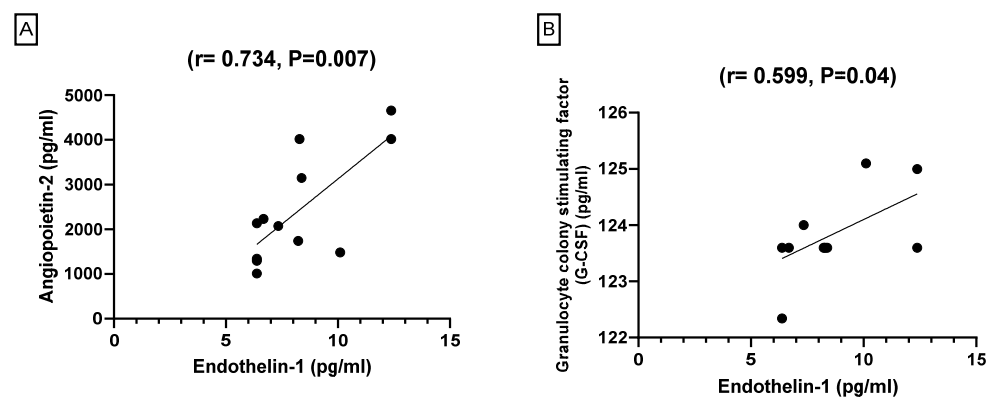

C
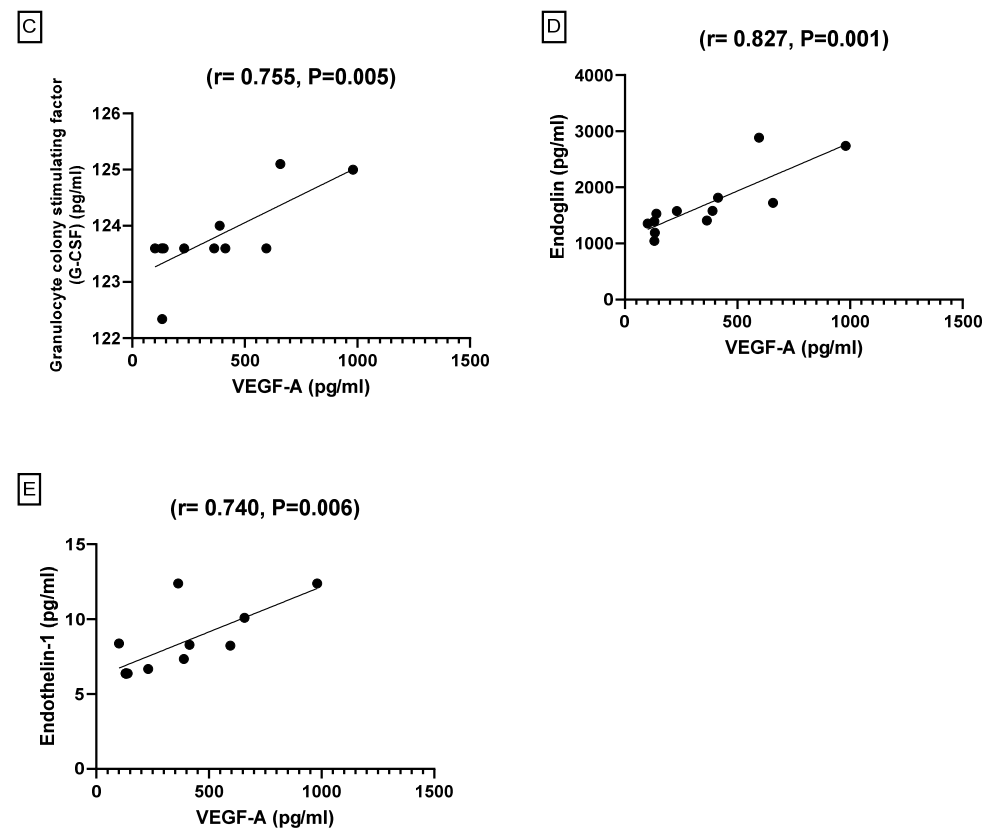

Figure 6. Correlations between Endothelin-1 and angiopoietin-2 (A) and G-CSF (B). Correlations between VEGF-A and Endothelin-1 (C), endoglin (E), G-CSF and (D). 


\section{Discussion}

Stroke is the most debilitating condition for human wellbeing. Various animal models were used in previous studies to mimic ischemic human stroke with different occlusion intervals [21]. In the present study, intra-aluminum filament techniques were used to induce the MCAO model in albino rats. This method results in an interference with blood flow to the MCA from ICA. MCAO is a useful experimental model for focal cerebral ischemia, which causes chronic infarction in the areas supplied by it [22].

For ischemic brain lesions, the focus is not on the secondary injury, which has recently attracted researchers' attention, but only on the clinical and histological improvements at the site of ischemia. Other studies have indicated that neurological trauma to the brain was not limited to a regional infarction but also contributed to exofocal post-ischemic neuronal deaths $[22,23]$. According to Zhao et al., the MCAO rat's substantia nigra was losing healthy neurons and increasing astrocyte proliferation [24]. In the spinal cord, hippocampus, hypothalamic, and substantia nigra pars reticulata regions following focal cerebral ischemic lesions, secondary changes in the form of activated microglia and astrocytes were also observed [25-27].

In this study, cerebellar changes were observed for rats following MCAO. The results of $\mathrm{H} \& \mathrm{E}$ stained cerebellar sections exhibited degenerative histological changes in the MCAO group. Similar findings were observed by $[7,23]$. Jie and his colleagues found apoptosis of neural cells of the cerebellar cortex in the MCAO group by the electron transmission microscope and further confirmed the results by TUNEL assay. They reported that the apoptotic cell count was increasing dynamically in MCAO compared to the control group by the time of the MCAO. They explained that the apoptosis mechanism of the cerebellar cortex neural cells was triggered after MCAO, probably due to the disruption of the pathways of the nerves.

A consequence of a neuronal injury is a simple disruption to neural cells and axonal degeneration. The apoptosis of cerebellar cortex neural cells caused by MCAO may be linked to the disruption of cortical pathways [23]. In comparison, some authors observed and regarded shrunk Purkinje cells with darkly stained cytoplasm and undefined nuclei as a sign of chromatolysis and gliosis. Rapid response to brain damage that is mediated by soluble neuron mediators or cell-cell interaction may be clarified by gliosis or decreased neuralgic cells. Other researchers considered dark shrunk neurons as a mirror with a much-condensed cytoplasm and nucleoplasm [28,29].

The cytoplasm of Purkinje cells in Nissl stained cerebellum areas from the MCAO group showed that some Purkinje cells were stained slightly compared to the sham control group, where the content of Nissl's granules was apparently decreased. The process is called chromatolysis, which Hanz and Fainzilber explained [30]. They stated that a neuronal cytoplasm reaction occurs following traumatic or metabolic damage.

Regarding the cytoplasmic immune reaction of the GFAP in the astrocyte cell body and the processes thereof, there was a significant increase in contrast with the sham control group in the MCAO rats. GFAP is the mature astrocyte intermediate filament; after, it is known as specific astrocyte markers [31]. Published investigations suggested that any degenerative brain injury could trigger the proliferation of astrocytes and hypertrophy, resulting in severe astrogliosis with increased GFAP positive reactions. The presence of these neuronal astrocytes as a result of neurodegeneration can be seen as a compensatory mechanism. Such activated astrocytes benefit tissue repair after injury by tracking $\mathrm{pH}$, ion homeostasis, and extracellular fluid. Astrocytes, through over-activation, can, however, lead to adverse effects [29,32].

The selection of the growth factors evaluated in the present study (angiopoietin2, VEGF-A, and G-CSF) was performed due to previous pre-clinical models of cerebral ischemia $[33,34]$. In this study, there was a significant increase in the serum level of the growth factors angiopoietin-2 and VEGF-A in the MCAO group compared to the sham control group. There was an increase in G-CSF serum level in the MCAO rats but this was non-significant when compared to the control rats. In addition, there were significant 
positive correlations between VEGF-A and G-CSF. Similar findings were observed by [35]. Sobrino and his colleagues reported that the serum level of VEGF, CF, Ang-1, and stromalrelated factor- $1 \alpha$ showed a similar biological trend with maximum values at day seven and remained higher in the first three months [35].

G-CSF promotes the mobilization of stem cells from the bone marrow into compromised brain areas, reducing infarction and increasing plasticity and vascularization of the neuron [36-38]. The G-CSF showed a slight enhancement in function but not in neurological impairment [33]. While Ang-1 may be the interaction between neurogenesis and angiogenesis, it facilitates neuron migration and functional recovery after ischemic stroke [35,39,40]. Similar findings were observed by Zhang and his colleagues, who reported that there was a significant increase in serum level of the angiopoietin- 1 in the mice model of the ischemic brain induced by embolic MCAO. They explained that angiopoietin-1 reduces BBB leakage and consequently decreases ischemic lesion volume [41]. After the ischemic injury, VEGF and angiopoietin-1 play a significant role in angiogenesis [42]. Angiopoietin-1 supports angiogenesis and new vessel remodeling. It is also an anti-permeability factor and recruits vascular smooth muscle cells and pericytes to surround endothelial cells so that new blood vessels are eventually developed and stabilized [43].

The VEGF family includes five members for primates, including Placental Growth Factor and VEGF-A/B/C/D.

The VEGF-A molecule is exceptional in this family due to its ability to facilitate neuroprotection and angiogenesis [44-48]. VEGF is a central angiogenesis regulator in an animal stroke model. Increasing vessel density in the peri-infarct zone follows VEGF expression [18,49-53]. Furthermore, VEGF causes astrocyte trans-differentiation into new neurons after acute ischemic strokes and, thus, facilitates neurogenesis [54]. In the setting of acute ischemic stroke, it makes VEGF-A's supportive role in both angiogenesis and neurogenesis an attractive molecular objective for rational drug therapy. Under these conditions, in the early recovery phase following acute ischemic stroke, the rise in endogenous VEGF concentrations and the use of exogenous VEGF in ischemic brains are potentially injurious [55]. The dual role of VEGF-A in acute ischemic stroke is by creating an endothelial network by enhancing endothelial cell migration and proliferation, and it also induces vascular leakage and permeability [56]. Additionally, a recent research study in a rodent MCAO model of acute ischemic stroke by Zhang and his colleagues stated that upregulation in the matrix metalloproteinases (MMPs) could contribute to cerebrovascular edema caused by VEGF-A and inflammatory disruption in the acute ischemic stroke. They also concluded that early VEGF secretion would contribute to endothelial leakage after acute ischemic stroke, premature inhibition of VEGF, and a decrease in neurovascular permeability with decreased neurological function. They also stated that these neuroprotective effects would decrease rates of MMP 2 and 9 and, at the same time, increase tight junction proteins such as occludin [53]. Therefore, VEGF and Ang-1 exert synergistic effects on angiogenesis after stroke [57]. Lee et al. found that higher levels of VEGF-A lead to improving results in stock recovery, contrary to this research [58]. Furthermore, Matsuo et al. found that the VEGF-A concentration correlated positively to the severity of the stroke in cardioembolic infarction and correlated negatively with the severity of the extent of the atherothrombotic infarction [59].

Endoglin is an essential molecule in physiological and pathological vascular changes. Endoglin is the most critical element in endoglin-deficient mouse angiogenesis and vascular remodeling studies. Endoglin is present in Endothelial cells with relatively low levels of physiological conditions, but expression increases in Endoglin during angiogenesis and vascular damage [60]. VEGF-A induces endothelial activation by binding to vascular endothelial growth factor receptor two and subsequent leukocyte extravasation. In addition, endoglin expression is linked to inflammation in the endothelial function [61,62]. This could explain why there was a significant positive correlation between VEGF-A and endoglin in the present study. 
Endothelin-1 can be a potential biomarker for BBB dysfunction as ET-1 overexpression contributes to further deposition of fluid and brain edema in experimental models following MCAO [63]. In acute phases, ET-1 controls the endothelial function that mediates vasoconstriction or vasodilation depending on the receptor, and contributes to increased permeability of the BBB $[64,65]$. In addition, high levels of ET-1 serum were found in ischemic patients $[63,65]$. This could explain why the ET-1 serum in the MCAO group was significantly higher than in the control group.

\section{Conclusions}

In conclusion, the secondary injury of the cerebellar cortex could be investigated by using middle cerebral occlusion in rats as an example. In addition, in the present study, prominent findings revealed valuable insights into the association and interaction between altered levels of angiogenic factors and acute ischemic stroke induced by middle cerebral artery occlusion in rats. Therefore, with the generation of significant results, it seems necessary to routinely monitor the angiogenic factor levels during acute ischemic stroke to decide proper intervention to stop the harmful outcomes of cerebral stroke and neurological deficiency.

Funding: This research was funded by the Deanship of Scientific Research (DSR), at King Abdulaziz University, Jeddah, Saudi Arabia, grant number G:30-290-1442.

Institutional Review Board Statement: The study was designed with correspondence to the codes of the guidelines for Ethical Conduct in the Care and Use of Animals; experimental conduct and handling were authorized via the Animal Ethics division within the Ethics Committee of Biomedical Research-Faculty of Medicine at King Abdulaziz University, (Reference No. 237-20, 31 May 2020). The experiment was executed in consensus with the guidelines of dealing with experimental animals that are followed in KFMRC, KAU, Jeddah, Saudi Arabia, which are in accordance with the Canadian Council for animal safety and health care.

Informed Consent Statement: Not applicable.

Data Availability Statement: The data used to support the findings of this study were included within the article.

Acknowledgments: We thank DSR for funding this project. This project was funded by the Deanship of Scientific Research (DSR), at KAU, Jeddah, under Grant no. G:30-290-1442. Therefore, the author acknowledges DSR for technical and financial support.

Conflicts of Interest: The author declares no conflict of interest.

\section{References}

1. Genovese, T.; Impellizzeri, D.; Ahmad, A.; Cornelius, C.; Campolo, M.; Cuzzocrea, S.; Esposito, E. Post-ischaemic thyroid hormone treatment in a rat model of acute stroke. Brain Res. 2013, 1513, 92-102. [CrossRef] [PubMed]

2. Asirvatham, A.R.; Marwan, M.Z. Stroke in Saudi Arabia: A review of the recent literature. Pan Afr. Med. J. 2014, 17, 14. [CrossRef]

3. Tran, J.; Mirzaei, M.; Anderson, L.; Leeder, S.R. The epidemiology of stroke in the Middle East and North Africa. J. Neurol. Sci. 2010, 295, 38-40. [CrossRef] [PubMed]

4. Al-Jadid, M.S.; Robert, A.A. Determinants of length of stay in an inpatient stroke rehabilitation unit in Saudi Arabia. Saudi Med. J. 2010, 31, 189-192. [PubMed]

5. Finger, S.; Koehler, P.J.; Jagella, C. The Monakow concept of diaschisis: Origins and perspectives. Arch. Neurol. 2004, 61, 283-288. [CrossRef] [PubMed]

6. Baron, J.C.; Bousser, M.G.; Comar, D.; Castaigne, P. ‘Crossed cerebellar diaschisis' in human supratentorial brain infarction. Trans. Am. Neurol. Assoc. 1981, 105, 459-461.

7. Kidani, N.; Hishikawa, T.; Hiramatsu, M.; Nishihiro, S.; Kin, K.; Takahashi, Y.; Murai, S.; Sugiu, K.; Yasuhara, T.; Miyazaki, I.; et al. Cerebellar Blood Flow and Gene Expression in Crossed Cerebellar Diaschisis after Transient Middle Cerebral Artery Occlusion in Rats. Int. J. Mol. Sci. 2020, 21, 4137. [CrossRef]

8. Gold, L.; Lauritzen, M. Neuronal deactivation explains decreased cerebellar blood flow in response to focal cerebral ischemia or suppressed neocortical function. Proc. Natl. Acad. Sci. USA 2002, 99, 7699-7704. [CrossRef]

9. Liu, Y.; Karonen, J.; Nuutinen, J.; Vanninen, E.; Kuikka, J.T.; Vanninen, R.L. Crossed cerebellar diaschisis in acute ischemic stroke: A study with serial SPECT and MRI. J. Cereb. Blood Flow Metab. 2007, 27, 1724-1732. [CrossRef] 
10. Vendrame, M.; Gemma, C.; De Mesquita, D.; Collier, L.; Bickford, P.; Sanberg, C.D.; Sanberg, P.R.; Pennypacker, K.R.; Willing, A.E. Anti-inflammatory Effects of Human Cord Blood Cells in a Rat Model of Stroke. Stem Cells Dev. 2005, 14, 595-604. [CrossRef]

11. Hu, Z.; Xia, H.; Yang, Y.; Zheng, H.; Zhao, L.; Chen, Y.; Zhuge, Q.; Xia, N.; Gao, H.; Chen, W. Metabolic alterations in the rat cerebellum following acute middle cerebral artery occlusion, as determined by 1H NMR spectroscopy. Mol. Med. Rep. 2018, 17, 531-541. [CrossRef] [PubMed]

12. Wang, Y.; Zhang, R.; Xing, X.; Guo, J.; Xie, F.; Zhang, G.; Qin, X. Repulsive guidance molecule a suppresses angiogenesis after ischemia/reperfusion injury of middle cerebral artery occlusion in rats. Neurosci. Lett. 2018, 662, 318-323. [CrossRef] [PubMed]

13. Lennmyr, F.; Terént, A.; Syvänen, A.C.; Barbany, G. Vascular endothelial growth factor gene expression in middle cerebral artery occlusion in the rat. Acta Anaesthesiol. Scand. 2005, 49, 488-493. [CrossRef] [PubMed]

14. Liu, J.; Ma, Y.; Dou, S.; Wang, Y.; La, D.; Liu, J.; Ma, Z. Hemodynamic changes in a rat parietal cortex after endothelin-1-induced middle cerebral artery occlusion monitored by optical coherence tomography. J. Biomed. Opt. 2016, 21, 75014. [CrossRef]

15. Lo, A.C.Y.; Chen, A.Y.S.; Hung, V.K.L.; Yaw, L.P.; Fung, M.K.L.; Ho, M.C.Y.; Tsang, M.C.S.; Chung, S.S.M.; Chung, S.K. Endothelin1 overexpression leads to further water accumulation and brain edema after middle cerebral artery occlusion via aquaporin 4 expression in astrocytic end-feet. J. Cereb. Blood Flow Metab. 2005, 25, 998-1011. [CrossRef]

16. Shyu, W.-C.; Lin, S.-Z.; Lee, C.-C.; Liu, D.D.; Li, H. Granulocyte colony-stimulating factor for acute ischemic stroke: A randomized controlled trial. CMAJ 2006, 174, 927-933. [CrossRef]

17. Schaäbitz, W.-R.; Schneider, A. Developing granulocyte-colony stimulating factor for the treatment of stroke: Current status of clinical trials. Stroke 2006, 37, 1654. [CrossRef]

18. Matchett, G.A.; Calinisan, J.B.; Matchett, G.C.; Martin, R.D.; Zhang, J.H. The effect of granulocyte-colony stimulating factor in global cerebral ischemia in rats. Brain Res. 2007, 1136, 200-207. [CrossRef]

19. Longa, E.Z.; Weinstein, P.R.; Carlson, S.; Cummins, R. Reversible middle cerebral artery occlusion without craniectomy in rats. Stroke 1989, 20, 84-91. [CrossRef]

20. Boyko, M.; Zlotnik, A.; Gruenbaum, B.F.; Gruenbaum, S.E.; Ohayon, S.; Goldsmith, T.; Kotz, R.; Leibowitz, A.; Sheiner, E.; Shapira, Y.; et al. An experimental model of focal ischemia using an internal carotid artery approach. J. Neurosci. Methods 2010, 193, 246-253. [CrossRef]

21. Shah, F.A.; Li, T.; Al Kury, L.T.; Zeb, A.; Khatoon, S.; Liu, G.; Yang, X.; Liu, F.; Yao, H.; Khan, A.-U.; et al. Pathological Comparisons of the Hippocampal Changes in the Transient and Permanent Middle Cerebral Artery Occlusion Rat Models. Front. Neurol. 2019, 10, 1178. [CrossRef]

22. Boyko, M.; Kutz, R.; Gruenbaum, B.F.; Cohen, H.; Kozlovsky, N.; Gruenbaum, S.E.; Shapira, Y.; Zlotnik, A. The influence of aging on poststroke depression using a rat model via middle cerebral artery occlusion. Cogn. Affect. Behav. Neurosci. 2013, 13, 847-859. [CrossRef]

23. Jie, L.; Yuqin, C.; Yao, D.; Shuai, H.; Yuanyuan, W. Occlusion of middle cerebral artery induces apoptosis of cerebellar cortex neural cells via caspase-3 in rats. Turk. Neurosurg. 2011, 21, 567-574. [CrossRef]

24. Zhao, F.; Kuroiwa, T.; Miyasaka, N.; Nagaoka, T.; Nakane, M.; Tamura, A.; Mizusawa, H. Characteristic changes in T2-value, apparent diffusion coefficient, and ultrastructure of substantia nigra evolving exofocal postischemic neuronal death in rats. Brain Res. 2001, 895, 238-244. [CrossRef]

25. Dihné, M.; Grommes, C.; Lutzenburg, M.; Witte, O.W.; Block, F. Different mechanisms of secondary neuronal damage in thalamic nuclei after focal cerebral ischemia in rats. Stroke 2002, 33, 3006-3011. [CrossRef]

26. Loos, M.; Dihne, M.; Block, F. Tumor necrosis factor- $\alpha$ expression in areas of remote degeneration following middle cerebral artery occlusion of the rat. Neuroscience 2003, 122, 373-380. [CrossRef]

27. Zhang, J.; Zhang, Y.; Xing, S.; Liang, Z.; Zeng, J. Secondary neurodegeneration in remote regions after focal cerebral infarction: A new target for stroke management? Stroke 2012, 43, 1700-1705. [CrossRef] [PubMed]

28. Afifi, O.K. Effect of sodium fluoride on the cerebellar cortex of adult albino rats and the possible protective role of vitamin B6: A light and electron microscopic study. Egypt. J. Histol. 2009, 32, 358-367.

29. El-Dien, S.H.M.; el Gamal, D.A.; Mubarak, H.A.; Saleh, S.M. Effect of fluoride on rat cerebellar cortex: Light and electron microscopic studies. Egypt. J. Histol. 2010, 33, 245-246.

30. Hanz, S.; Fainzilber, M. Retrograde signaling in injured nerve-the axon reaction revisited. J. Neurochem. 2006, 99, 13-19. [CrossRef]

31. Kassab, A.A. Wheat germ oil attenuates deltamethrin-induced injury in rat cerebellar cortex: Histological and immunohistochemical study. Egypt. J. Histol. 2018, 41, 182-191. [CrossRef]

32. Hashem, H.E.; Safwat, M.D.E.-D.; Algaidi, S. The effect of monosodium glutamate on the cerebellar cortex of male albino rats and the protective role of vitamin C (histological and immunohistochemical study). J. Mol. Histol. 2012, 43, 179-186. [CrossRef] [PubMed]

33. Huang, X.; Liu, Y.; Bai, S.; Peng, L.; Zhang, B.; Lu, H. Granulocyte colony stimulating factor therapy for stroke: A pairwise meta-analysis of randomized controlled trial. PLoS ONE 2017, 12, e0175774. [CrossRef] [PubMed]

34. Chan, S.J.; Love, C.; Spector, M.; Cool, S.M.; Nurcombe, V.; Lo, E.H. Endogenous regeneration: Engineering growth factors for stroke. Neurochem. Int. 2017, 107, 57-65. [CrossRef] [PubMed]

35. Sobrino, T.; Rodríguez-Yáñez, M.; Campos, F.; Iglesias-Rey, R.; Millán, M.; De La Ossa, N.P.; Dávalos, A.; Delgado-Mederos, R.; Martínez-Domeño, A.; Martí-Fábregas, J.; et al. Association of High Serum Levels of Growth Factors with Good Outcome in Ischemic Stroke: A Multicenter Study. Transl. Stroke Res. 2019, 11, 653-663. [CrossRef] [PubMed] 
36. Schneider, A.; Krüger, C.; Steigleder, T.; Weber, D.; Pitzer, C.; Laage, R.; Aronowski, J.; Maurer, M.; Gassler, N.; Mier, W.; et al. The hematopoietic factor G-CSF is a neuronal ligand that counteracts programmed cell death and drives neurogenesis. J. Clin. Investig. 2005, 115, 2083-2098. [CrossRef]

37. Shyu, W.-C.; Lin, S.-Z.; Yang, H.-I.; Tzeng, Y.-S.; Pang, C.-Y.; Yen, P.-S.; Li, H. Functional recovery of stroke rats induced by granulocyte colony-stimulating factor-stimulated stem cells. Circulation 2004, 110, 1847-1854. [CrossRef] [PubMed]

38. Morita, Y.; Takizawa, S.; Kamiguchi, H.; Uesugi, T.; Kawada, H.; Takagi, S. Administration of hematopoietic cytokines increases the expression of anti-inflammatory cytokine (IL-10) mRNA in the subacute phase after stroke. Neurosci. Res. 2007, 58, 356-360. [CrossRef]

39. Ohab, J.J.; Fleming, S.; Blesch, A.; Carmichael, S.T. A neurovascular niche for neurogenesis after stroke. J. Neurosci. 2006, 26, 13007-13016. [CrossRef]

40. Cui, X.; Chen, J.; Zacharek, A.; Roberts, C.; Yang, Y.; Chopp, M. Nitric oxide donor up-regulation of SDF1/CXCR4 and Ang1/Tie2 promotes neuroblast cell migration after stroke. J. Neurosci. Res. 2009, 87, 86-95. [CrossRef]

41. Zhang, Z.G.; Zhang, L.; Croll, S.D.; Chopp, M. Angiopoietin-1 reduces cerebral blood vessel leakage and ischemic lesion volume after focal cerebral embolic ischemia in mice. Neuroscience 2002, 113, 683-687. [CrossRef]

42. Hui, Z.; Sha, D.-J.; Wang, S.-L.; Li, C.-S.; Qian, J.; Wang, J.-Q.; Zhao, Y.; Zhang, J.-H.; Cheng, H.-Y.; Yang, H.; et al. Panaxatriol saponins promotes angiogenesis and enhances cerebral perfusion after ischemic stroke in rats. BMC Complement. Altern. Med. 2017, 17, 70. [CrossRef]

43. Zhao, J.; Chen, L.; Shu, B.; Tang, J.; Zhang, L.; Xie, J.; Qi, S.; Xu, Y. Granulocyte/macrophage colony-stimulating factor influences angiogenesis by regulating the coordinated expression of VEGF and the Ang/Tie system. PLoS ONE 2014, 9, e92691. [CrossRef]

44. Góra-Kupilas, K.; Jośko, J. The neuroprotective function of vascular endothelial growth factor (VEGF). Folia Neuropathol. 2005, 43, 31-39.

45. Cao, L.; Jiao, X.; Zuzga, D.S.; Liu, Y.; Fong, D.M.; Young, D.; During, M.J. VEGF links hippocampal activity with neurogenesis, learning and memory. Nat. Genet. 2004, 36, 827-835. [CrossRef] [PubMed]

46. Dzietko, M.; Derugin, N.; Wendland, M.F.; Vexler, Z.S.; Ferriero, D.M. Delayed VEGF treatment enhances angiogenesis and recovery after neonatal focal rodent stroke. Transl. Stroke Res. 2013, 4, 189-200. [CrossRef]

47. Nishijima, K.; Ng, Y.-S.; Zhong, L.; Bradley, J.; Schubert, W.; Jo, N.; Akita, J.; Samuelsson, S.J.; Robinson, G.S.; Adamis, A.P.; et al. Vascular endothelial growth factor-A is a survival factor for retinal neurons and a critical neuroprotectant during the adaptive response to ischemic injury. Am. J. Pathol. 2007, 171, 53-67. [CrossRef]

48. Ma, Y.; Zechariah, A.; Qu, Y.; Hermann, D.M. Effects of vascular endothelial growth factor in ischemic stroke. J. Neurosci. Res. 2012, 90, 1873-1882. [CrossRef]

49. Sahota, P.; Savitz, S.I. Investigational therapies for ischemic stroke: Neuroprotection and neurorecovery. Neurotherapeutics 2011, 8 , 434-451. [CrossRef] [PubMed]

50. Marti, H.J.; Bernaudin, M.; Bellail, A.; Schoch, H.; Euler, M.; Petit, E.; Risau, W. Hypoxia-induced vascular endothelial growth factor expression precedes neovascularization after cerebral ischemia. Am. J. Pathol. 2000, 156, 965-976. [CrossRef]

51. Schoch, H.J.; Fischer, S.; Marti, H.H. Hypoxia-induced vascular endothelial growth factor expression causes vascular leakage in the brain. Brain 2002, 125, 2549-2557. [CrossRef] [PubMed]

52. Chen, B.; Zhang, F.; Li, Q.-Y.; Gong, A.; Lan, Q. Protective effect of Ad-VEGF-Bone mesenchymal stem cells on cerebral infarction. Turk. Neurosurg. 2016, 26, 8-15. [CrossRef] [PubMed]

53. Zhang, H.-T.; Zhang, P.; Gao, Y.; Li, C.-L.; Wang, H.-J.; Chen, L.-C.; Feng, Y.; Li, R.-Y.; Li, Y.-L.; Jiang, C.-L. Early VEGF inhibition attenuates blood-brain barrier disruption in ischemic rat brains by regulating the expression of MMPs. Mol. Med. Rep. 2017, 15, 57-64. [CrossRef] [PubMed]

54. Shen, S.-W.; Duan, C.-L.; Chen, X.-H.; Wang, Y.-Q.; Sun, X.; Zhang, Q.-W.; Cui, H.-R.; Sun, F.-Y. Neurogenic effect of VEGF is related to increase of astrocytes transdifferentiation into new mature neurons in rat brains after stroke. Neuropharmacology 2016, 108, 451-461. [CrossRef]

55. Kanazawa, M.; Igarashi, H.; Kawamura, K.; Takahashi, T.; Kakita, A.; Takahashi, H.; Nakada, T.; Nishizawa, M.; Shimohata, T. Inhibition of VEGF signaling pathway attenuates hemorrhage after tPA treatment. J. Cereb. Blood Flow Metab. 2011, 31, 1461-1474. [CrossRef]

56. Cosky, E.E.P.; Ding, Y. The role of vascular endothelial growth factor in angiogenesis and brain circulation after stroke. Brain Circ. 2018, 4, 73-75. [CrossRef] [PubMed]

57. Zacharek, A.; Chen, J.; Li, A.; Cui, X.; Li, Y.; Roberts, C.; Feng, Y.; Gao, Q.; Chopp, M. Angiopoietin1/Tie2 and VEGF/Flk1 induced by MSC treatment amplifies angiogenesis and vascular stabilization after stroke. J. Cereb. Blood Flow Metab. 2007, 27, 1684-1691. [CrossRef] [PubMed]

58. Lee, S.; Lee, K.; Kim, Y.; Kim, S.H.; Koh, S.; Lee, Y.-J. Serum VEGF levels in acute ischaemic strokes are correlated with long-term prognosis. Eur. J. Neurol. 2010, 17, 45-51. [CrossRef]

59. Matsuo, R.; Ago, T.; Kamouchi, M.; Kuroda, J.; Kuwashiro, T.; Hata, J.; Sugimori, H.; Fukuda, K.; Gotoh, S.; Makihara, N.; et al. Clinical significance of plasma VEGF value in ischemic stroke-research for biomarkers in ischemic stroke (REBIOS) study. BMC Neurol. 2013, 13, 32. [CrossRef] 
60. Bus, P.; Gerrits, T.; Heemskerk, S.A.; Zandbergen, M.; Wolterbeek, R.; Bruijn, J.A.; Baelde, H.J.; Scharpfenecker, M. Endoglin Mediates Vascular Endothelial Growth Factor-A-Induced Endothelial Cell Activation by Regulating Akt Signaling. Am. J. Pathol. 2018, 188, 2924-2935. [CrossRef]

61. Torsney, E.; Charlton, R.; Parums, D.; Collis, M.; Arthur, H.M. Inducible expression of human endoglin during inflammation and wound healing in vivo. Inflamm. Res. 2002, 51, 464-470. [CrossRef]

62. Dijke, P.T.; Goumans, M.-J.; Pardali, E. Endoglin in angiogenesis and vascular diseases. Angiogenesis 2008, 11, 79-89. [CrossRef]

63. Moldes, O.; Sobrino, T.; Millán, M.; Castellanos, M.; de la Ossa, N.P.; Leira, R.; Serena, J.; Vivancos, J.; Dávalos, A.; Castillo, J. High serum levels of endothelin-1 predict severe cerebral edema in patients with acute ischemic stroke treated with t-PA. Stroke 2008, 39, 2006-2010. [CrossRef] [PubMed]

64. Zhou, Y.; Dirksen, W.P.; Zweier, J.L.; Periasamy, M. Endothelin-1-induced responses in isolated mouse vessels: The expression and function of receptor types. Am. J. Physiol. Circ. Physiol. 2004, 287, H573-H578. [CrossRef] [PubMed]

65. Andresen, J.; Shafi, N.I.; Bryan, R.M., Jr. Endothelial influences on cerebrovascular tone. J. Appl. Physiol. 2006, $100,318-327$. [CrossRef] 